\title{
PROPRIEDADES FÍSICO - MECÂNICAS E AMBIENTAL DE CERÂMICA ESTRUTURAL COM ESTABILIZAÇÃO DO ÍON MANGANÊS
}

\author{
A. P. C. Câmara', L. C. de Medeiros², D. A. de Macedo' ${ }^{2}$ D. M. de A. Melo e M. A. de F. Melo' \\ ${ }^{1}$ Programa de Pós-Graduação em Engenharia Química/UFRN, 59072-970, Natal, RN, Brasil \\ ${ }^{2}$ Programa de Pós-Graduação em Ciência e Engenharia de Materiais/UFRN, 59072-970, Natal, RN, Brasil \\ anapaulacceq@gmail.com / alg_leonardo@hotmail.com / damaced@gmail.com / daraujomelo@gmail.com / \\ mafm.ufrn@gmail.com
}

Artigo submetido em setembro/2012 e aceito em outubro/2012

\section{RESUMO}

Neste trabalho estudou-se a adição do íon manganês bivalente a uma massa argilosa do estado do Rio Grande do Norte a fim de avaliar a viabilidade tecnológica e ambiental do material cerâmico. A matéria-prima cerâmica foi caracterizada por análise química (FRX) e difratometria de raios $X$ (DRX). O íon metálico foi adicionado na forma de soluções aquosas nas concentrações de 100, 150 e 200 mg/l. Os corpos de prova obtidos por extrusão e sinterizados nas temperaturas de 850,950 e $1050^{\circ} \mathrm{C}$ foram avaliados por ensaios cerâmicos e ambiental de solubilidade. As propriedades tecnológicas examinadas foram: retração linear de queima, absorção de água, porosidade aparente, massa específica aparente e tensão de ruptura à flexão em três pontos. Segundo essa avaliação a porosidade aparente e absorção de água permaneceram praticamente constantes, apenas variações singulares foram observadas em função da concentração do íon manganês. Por outro lado, constatou-se um crescimento na tensão de ruptura à flexão com o aumento da temperatura, independente, da concentração do íon. A análise dos resultados indicou que a cerâmica com o íon manganês incorporado e estabilizado, é adequada à fabricação de produtos cerâmicos, como tijolo maciço e revestimento semi-poroso, sem oferecer risco ao meio ambiente.

PALAVRAS-CHAVE: manganês, cerâmica, estabilização.

\section{PHYSICAL - MECHANICAL AND ENVIRONMENTAL PROPERTIES OF STRUCTURAL CERAMICS WITH STABILIZATION OF MANGANESE ION}

\section{ABSTRACT}

The main aim of this study was to evaluate the technological and environmental feasibility of adding divalent manganese ion into a clayey mass of Rio Grande do Norte. The ceramic raw material was characterized by XRF and XRD. The metal ion was added as aqueous solutions at concentrations of 100,150 and $200 \mathrm{mg} / \mathrm{L}$. The physical - mechanical and environmental properties of ceramic bodies were investigated after sintering between 850 and $1050^{\circ} \mathrm{C}$. The technological properties evaluated were: linear shrinkage, water absorption, apparent porosity, bulk density, and flexural strength ( 3 points). The results indicated that the ceramic with stabilization of the manganese ion is suitable for the manufacture of various ceramic products such as massive brick and semiporous tiles without offering risk to the environment.

KEY-WORDS: manganese, ceramic, stabilization. 
PROPRIEDADES FÍSICO-MECÂNICAS E AMBIENTAL DE CERÂMICA ESTRUTURAL COM

ESTABILIZAÇÃO DO ÍON MANGANÊS

\section{INTRODUÇÃO}

A técnica de estabilizar elementos e compostos químicos nocivos à saúde humana e ao meio ambiente é uma importante atividade que se desenvolve a fim de preservar os ecossistemas e reduzir a poluição das grandes fontes emissoras de poluentes tóxicos. Neste contexto, a argila é bastante utilizada como suporte de resíduos industriais, merecendo destaque as pesquisas com a finalidade de uso na construção civil. Moreira et al. (2001) estudaram a utilização do lodo de estação de tratamento de esgotos (ETE) de indústria têxtil para a fabricação de materiais de construção; Balaton et al. (2001) avaliaram os riscos ambientais da incorporação de lama galvânica em massa cerâmica vermelha; Alves e Holanda (2005) estudaram a adição de borra oleosa à massa argilosa para fabricação de blocos cerâmicos de vedação, o exame dos resultados indica que o teor de borra incorporado é inversamente proporcional à absorção de água e os ensaios de solubilidade classificaram os blocos produzidos como Classe II (não inertes). Camargo et al. (2005) investigaram os efeitos da adição dos metais cádmio, chumbo, cromo, cobre, níquel, zinco, manganês e cobalto, na forma de seus respectivos óxidos, em uma massa argilosa para produção de cerâmica estrutural.

Comparando-se com outros processos de remoção de metais pesados em efluentes industriais, tais como troca iônica e adsorção, que utilizam resinas iônicas, de acordo com Câmara (2009) a estabilização de resíduos na argila para fabricação de peças cerâmicas não gera outros resíduos, tornando-se um processo limpo para a obtenção de produtos cerâmicos com propriedades tecnológicas apropriadas e a baixo custo. Neste sentido, o presente trabalho consiste num processo alternativo ao tratamento final de efluentes, contendo o íon manganês bivalente, o íon metálico foi adicionado à argila na forma de soluções aquosas e estabilizado para produção de cerâmica estrutural.

\section{MATERIAIS E MÉTODOS}

\section{Obtenção da Matriz Cerâmica e do Íon Metálico}

A matéria-prima cerâmica utilizada, advinda da Indústria Cerâmica Caísa, (Goianinha, $\mathrm{RN}$ ), é a mesma utilizada pela indústria no seu processo produtivo. Para a obtenção do íon metálico manganês utilizou-se o sulfato de manganês hidratado, $\mathrm{MnSO}_{4} \cdot \mathrm{H}_{2} \mathrm{O}$ (Cromato Produtos Químicos Ltda). Efluentes sintéticos contendo 100, 150 e $200 \mathrm{mg}$ de sulfato de manganês obteve-se com a diluição preliminar em um becker de $50 \mathrm{ml}$ e em seguida transferência da amostra para balões volumétricos adicionando-se água destilada até completar o volume de 1,0 litro. Desta forma se produziu soluções aumentando em 100, 150 e 200 vezes o valor máximo permissível de $1,0 \mathrm{mg} / \mathrm{l}$ de manganês dissolvido, de acordo com as Condições e Padrões de Lançamento de Efluentes da Resolução no 357 do CONAMA segundo Brasil (2005). 


\section{Caracterização da Matéria-prima Cerâmica}

A caracterização química por fluorescência de raios $X$ (FRX) foi realizada na matériaprima sem adição do íon metálico. O resultado, expresso em porcentagem mássica dos óxidos, obteve-se utilizando um espectrômetro de fluorescência de raios $X$ da Shimadzu (EDX 720). As análises termogravimétricas (TG) e térmica diferencial (ATD) foram realizadas em equipamentos da Shimadzu $(51 / 51 \mathrm{H}$ e $50 / 50 \mathrm{H})$ utilizando taxa de aquecimento de $10^{\circ} \mathrm{C} / \mathrm{min}$ e atmosfera de ar. A caracterização mineralógica realizada por difração de raios $X$ (DRX) utilizando radiação $\mathrm{Cu} \mathrm{K} \alpha$ em um difratômetro da Shimadzu (XRD 6000). Com base nos resultados de FRX e de DRX foi realizada a análise racional da matéria-prima, para tanto utilizou-se o programa computacional "MIDS" de acordo com Varela et al. (2005).

\section{Preparação do Material Cerâmico}

Após as etapas de umidificação (com as soluções contendo o íon metálico) e laminação, os corpos de prova foram extrudados em uma extrusora Verdés, modelo 051 série 035. As amostras de dimensões $110 \times 29 \times 9 \mathrm{~mm}$ foram secas em estufa elétrica a $110^{\circ} \mathrm{C}$ por $24 \mathrm{~h}$ e tratadas termicamente entre 850 e $1050^{\circ} \mathrm{C}$ (isoterma de $3,0 \mathrm{~h}$ ) em forno elétrico de resistência Jung ${ }^{\circledR}$, № 4225, modelo 2314. No fluxograma da Figura 1 constam as etapas dos procedimentos experimentais relacionados aos estudos desenvolvidos na realização neste trabalho.

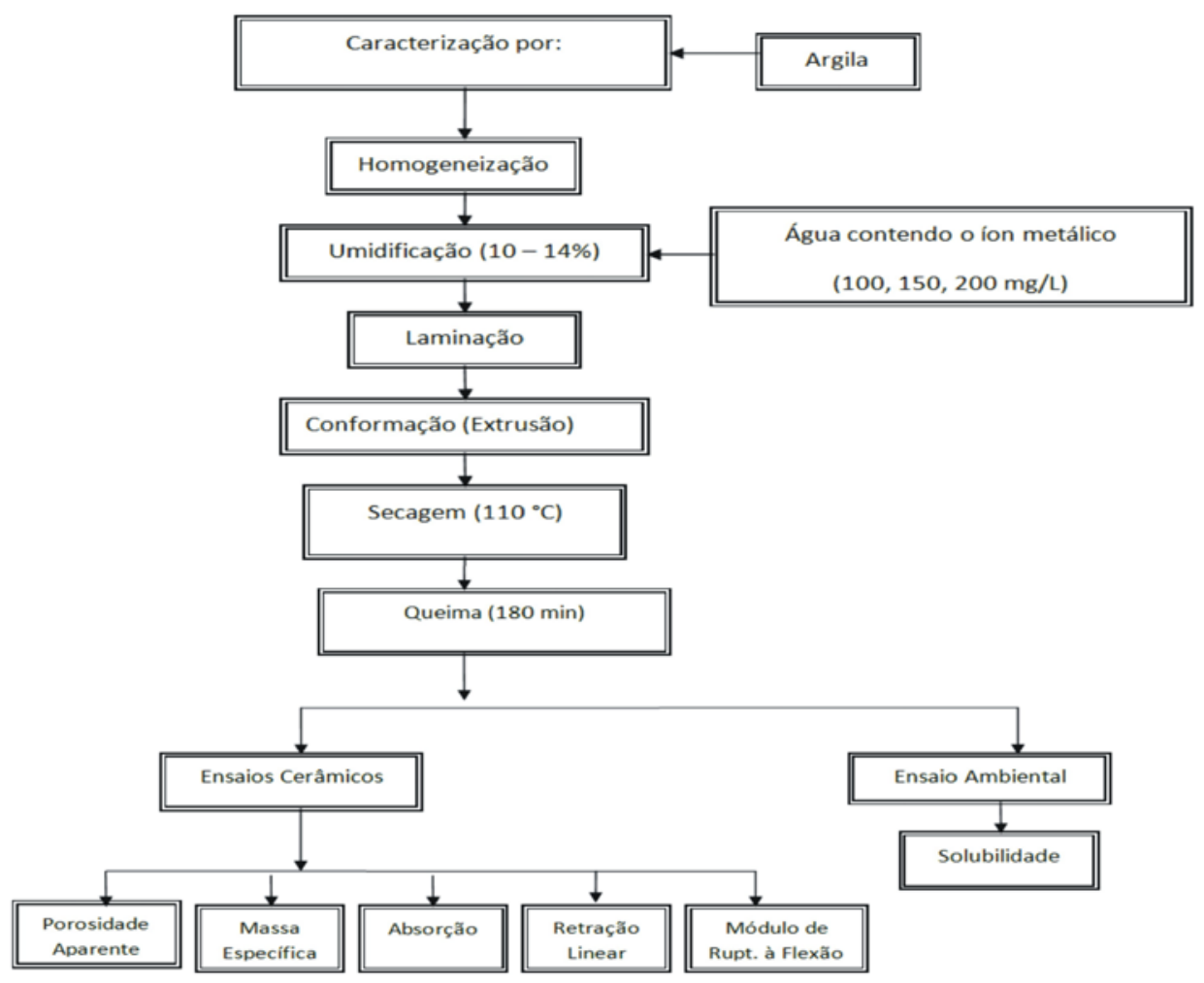

Figura 1 - Fluxograma do procedimento experimental para obtenção de corpos cerâmicos com incorporação de íon metálico. 
Preparou-se 3 (três) formulações, de acordo com os efluentes sintéticos. As formulações codificadas podem ser encontradas na Tabela 1.

Tabela 1: Formulações codificadas dos corpos cerâmicos.

\begin{tabular}{|c|c|c|}
\hline \multicolumn{3}{|c|}{ Formulações e Códigos } \\
\hline Argila $+100 \mathrm{mg} / \mathrm{l}$ & Argila $+150 \mathrm{mg} / \mathrm{l}$ & Argila $+200 \mathrm{mg} / \mathrm{l}$ \\
\hline $\mathrm{M}(-1)$ & $\mathrm{M}(0)$ & $\mathrm{M}(+1)$ \\
\hline
\end{tabular}

\section{Ensaios Cerâmicos e Ambiental}

Os corpos cerâmicos foram submetidos aos ensaios de absorção de água (AA), porosidade aparente (PA), massa específica aparente (MEA), retração linear de queima $\left(R L_{q}\right)$ e tensão de ruptura à flexão (TRF). Todos os ensaios foram realizados em duplicata, e seus resultados expresso como a média de seus valores utilizando as Equações 1, 2, 3, 4 e 5.

$\operatorname{AA}(\%)=\left(P_{u}-P_{s} / P_{s}\right) \times 100$

em que:

$\mathrm{P}_{\mathrm{u}}$ - peso do corpo de prova úmido $(\mathrm{g})$

$\mathrm{P}_{\mathrm{s}}$ - peso do corpo de prova seco $(\mathrm{g})$

$\mathbf{P A}(\%)=\left(\mathbf{P}_{\mathrm{u}}-\mathbf{P}_{\mathrm{s}} / \mathbf{P}_{\mathrm{u}}-\mathbf{P}_{\mathrm{i}}\right) \times 100$

em que:

$\mathrm{P}_{\mathrm{u}}$ - peso do corpo de prova úmido $(\mathrm{g})$

$\mathrm{P}_{\mathrm{s}}$ - peso do corpo de prova seco $(\mathrm{g})$

$\mathrm{P}_{\mathrm{i}}$ - peso do corpo de prova imerso em água $(\mathrm{g})$

$\operatorname{MEA}\left(\mathrm{g} / \mathrm{cm}^{3}\right)=$ PA $/$ AA ou MEA $\left(\mathrm{g} / \mathrm{cm}^{3}\right)=\mathbf{P}_{\mathrm{s}} / \mathbf{P}_{\mathrm{u}}-\mathbf{P}_{\mathrm{i}}$

$R_{q}(\%)=\left(L_{1}-L_{11} / L_{1}\right) \times 100$

em que:

$\mathrm{L}_{1}$ - Comprimento do corpo de prova após secagem de $110^{\circ} \mathrm{C}(\mathrm{cm})$

$\mathrm{L}_{11}$ - Comprimento do corpo de prova após queima $(\mathrm{cm})$

TRF $\left(\mathrm{Kgf} / \mathrm{cm}^{2}\right)=3$ PL/2bh'

em que:

P - carga atingida no momento da ruptura (kgf) 
$\mathrm{L}$ - a distância entre os apoios do corpo de prova $(\mathrm{cm})$

$\mathrm{b}=\mathrm{a}$ largura do corpo de prova $(\mathrm{cm})$

$\mathrm{h}$ - a altura do corpo de prova $(\mathrm{cm})$

Para o ensaio ambiental foi aplicado o procedimento contido na NBR 10006/2004 da $A B N T$, a determinação quantitativa do íon manganês contido no extrato solubilizado utilizouse a espectrometria de emissão ótica com plasma indutivamente acoplado (ICP/OES).

\section{RESULTADOS E DISCUSSÃO}

Na Tabela 2 estão relacionados os resultados da análise química semiquantitativa, em percentagem mássica dos respectivos óxidos, da matéria-prima em estudo. $\mathrm{O}$ alto teor de $\mathrm{SiO}_{2}$ (> 56\%) é atribuído à existência de silicatos, principalmente argilominerais, e ao quartzo livre. O quartzo, combinado com o $\mathrm{CaO}$, contribui para o aumento da resistência mecânica e diminuição da retração do material sinterizado, já que este se comporta como um "esqueleto" durante a formação da fase líquida. $\mathrm{O}$ óxido de alumínio $\left(\mathrm{Al}_{2} \mathrm{O}_{3}\right)$ está associado à ocorrência de caulinita. Outra importante informação é o elevado teor de $\mathrm{Fe}_{2} \mathrm{O}_{3}$, que é determinante para a coloração avermelhada das cerâmicas sinterizadas.

Tabela 2: Análise química da matéria-prima.

\begin{tabular}{|c|c|}
\hline Óxidos & Matéria-prima (\%) \\
\hline $\mathrm{SiO}_{2}$ & 56,39 \\
\hline $\mathrm{Al}_{2} \mathrm{O}_{3}$ & 27,20 \\
\hline $\mathrm{Fe}_{2} \mathrm{O}_{3}$ & 7,46 \\
\hline $\mathrm{K}_{2} \mathrm{O}$ & 3,90 \\
\hline $\mathrm{CaO}$ & 1,55 \\
\hline $\mathrm{TiO}_{2}$ & 1,09 \\
\hline $\mathrm{MnO}$ & 0,07 \\
\hline Outros & 2,28 \\
\hline
\end{tabular}

Verifica-se na figura 2 o difratograma de raios $x$ com a análise mineralógica da matériaprima. Foram identificados picos de difração referentes à caulinita $\left(\mathrm{Al}_{2}\left(\mathrm{Si}_{2} \mathrm{O}_{5}\right)\right.$. $\left.(\mathrm{HO})_{4}\right)$, quartzo $\left(\mathrm{SiO}_{2}\right)$ e microclínio $\left(\mathrm{KAlSi}_{3} \mathrm{O}_{8}\right)$. A análise racional obtida pelo programa computacional MIDS indica que a matéria-prima é constituída majoritariamente pela caulinita $(58,15 \%)$, seguida de quartzo $(14,2 \%)$, microclínio $(23,1 \%)$ e minerais acessórios $(4,41 \%)$. 


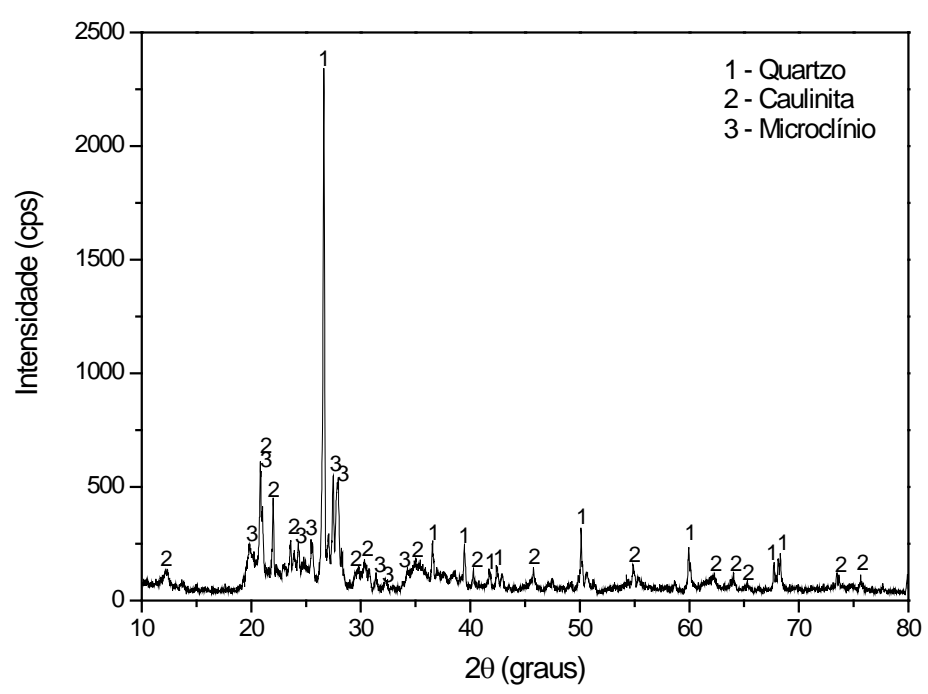

Figura 2 - Difratograma de raios $X$ da matéria-prima.

Observa-se na Figura 3 as curvas obtidas por análise termogravimétrica (TG) e análise térmica diferencial (ATD). Na curva relativa à TG constatam-se duas etapas de perda de massa, a primeira perda $(3,8 \%)$ ocorre até aproximadamente $120^{\circ} \mathrm{C}$, sendo atribuída à perda de água livre. A segunda etapa de perda $(3,3 \%)$ ocorre entre 400 e $600^{\circ} \mathrm{C}$, que se pode atribuir à decomposição de compostos orgânicos. Na curva de ATD há dois picos endotérmicos, o primeiro no intervalo de temperatura entre 50 e $120^{\circ} \mathrm{C}$ é relativo à desidratação e o segundo na faixa de temperatura entre 450 e $530^{\circ} \mathrm{C}$ refere-se à desidroxilação da caulinita em metacaulinita.

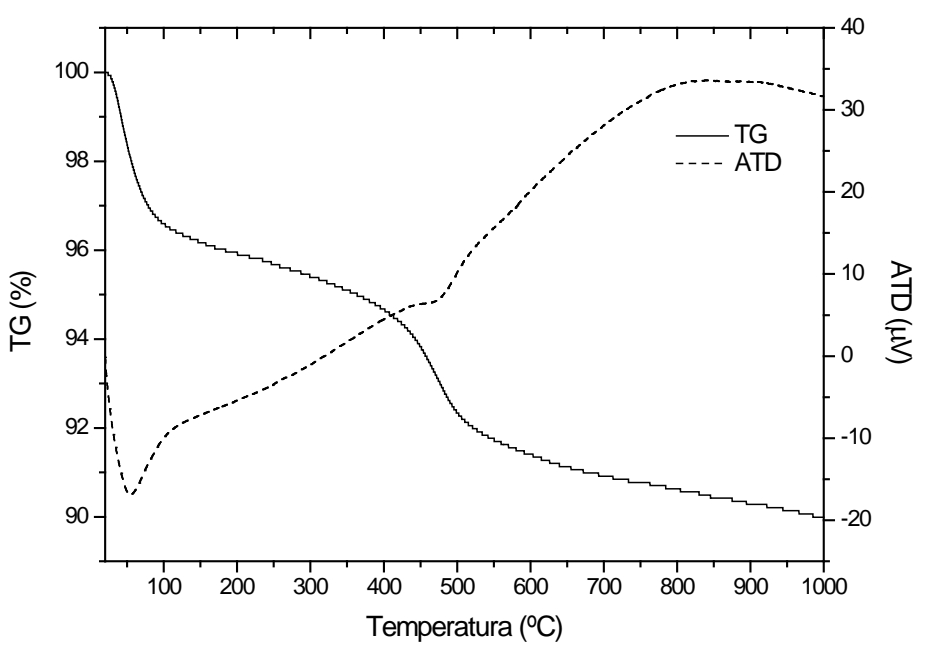

Figura 3 - TG e ATG da matéria-prima.

Nas Tabelas 3 e 4 estão relacionados os resultados dos ensaios cerâmicos das amostras contendo 100,150 e $200 \mathrm{mg} / \mathrm{l}$ do íon manganês e tratadas termicamente a 850, 950 e $1050^{\circ} \mathrm{C}$. Observou-se que a concentração de manganês não influi, de modo significativo, sobre os valores de AA, PA e MEA de peças obtidas numa mesma temperatura de sinterização. Por outro lado, o aumento de temperatura proporciona apreciável redução destas propriedades, 
a PA, por exemplo, assume valores inferiores a $20 \%$ (requerida para manter a integridade mecânica das peças nas operações de transporte) apenas na temperatura de $1050^{\circ} \mathrm{C}$. A apreciável existência de elementos fundentes na matéria-prima, comprovada pela análise racional, contribui para a diminuição da porosidade e consequente redução da absorção de água durante a formação de fase líquida a alta temperatura. Os resultados indicam que não há restrições quanto à fabricação de tijolos, blocos cerâmicos ou telhas ( $A A<20 \%$ ).

Após análise dos resultados da Tabela 4, pode-se afirmar que $R L_{q}$ decresce com $o$ aumento da concentração do íon manganês nas menores temperaturas e aumenta com o aumento da temperatura de queima, exibindo valor máximo de $2,89 \%$ a $1050^{\circ} \mathrm{C}$ e concentração de $200 \mathrm{mg} / \mathrm{l}$. Acredita-se que este fato relaciona-se às massas que possuem maior quantidade de fundentes e menor porosidade, cuja compensação é um aumento na retração linear da peça cerâmica. Os baixos valores de $R L_{q}(<4 \%)$ inserem-se na faixa apropriada para fabricação industrial de cerâmica vermelha. Este resultado é importante, uma vez que a obtenção de boa estabilidade dimensional das peças sinterizadas resultará na redução dos custos de produção. Os valores para a TRF permaneceram praticamente constantes entre 850 e $1050^{\circ} \mathrm{C}$ (para todas as concentrações do íon manganês).

Tabela 3: Ensaios cerâmicos: absorção de água, porosidade aparente e massa específica aparente.

\begin{tabular}{|c|c|c|c|c|c|c|c|c|c|c|c|c|}
\hline & AA (\%) & $\begin{array}{l}\mathrm{PA}(\%) \\
850^{\circ} \mathrm{C}\end{array}$ & $\operatorname{MEA}\left(\mathrm{g} / \mathrm{cm}^{3}\right)$ & AA $1 \%$ & $\begin{array}{l}\text { PA (\% } \\
950^{\circ} \mathrm{C}\end{array}$ & ) MEA & $\left(\mathrm{g} / \mathrm{cm}^{3}\right)$ & AA $(\%$ & $\begin{array}{r}\text { PA } \\
1\end{array}$ & $\begin{array}{l}\text { \%) } \mathrm{N} \\
50^{\circ} \mathrm{C}\end{array}$ & MEA & $\left(\mathrm{g} / \mathrm{cm}^{3}\right)$ \\
\hline$M(-1)$ & 12,04 & 23,24 & 1,93 & & 10,99 & 21,53 & 1,96 & & 8,85 & 17,7 & & 2,00 \\
\hline$M(0)$ & 12,09 & 23,36 & 1,93 & & 11,60 & 22,47 & 1,94 & & 9,51 & $18, \varepsilon$ & & 1,98 \\
\hline$M(+1)$ & 11,65 & 22,77 & 1,95 & & 11,18 & 21,84 & 1,97 & & 8,35 & 16, & ,81 & 2,02 \\
\hline
\end{tabular}


Tabela 4: Ensaios cerâmicos: retração linear de queima e tensão de ruptura à flexão.

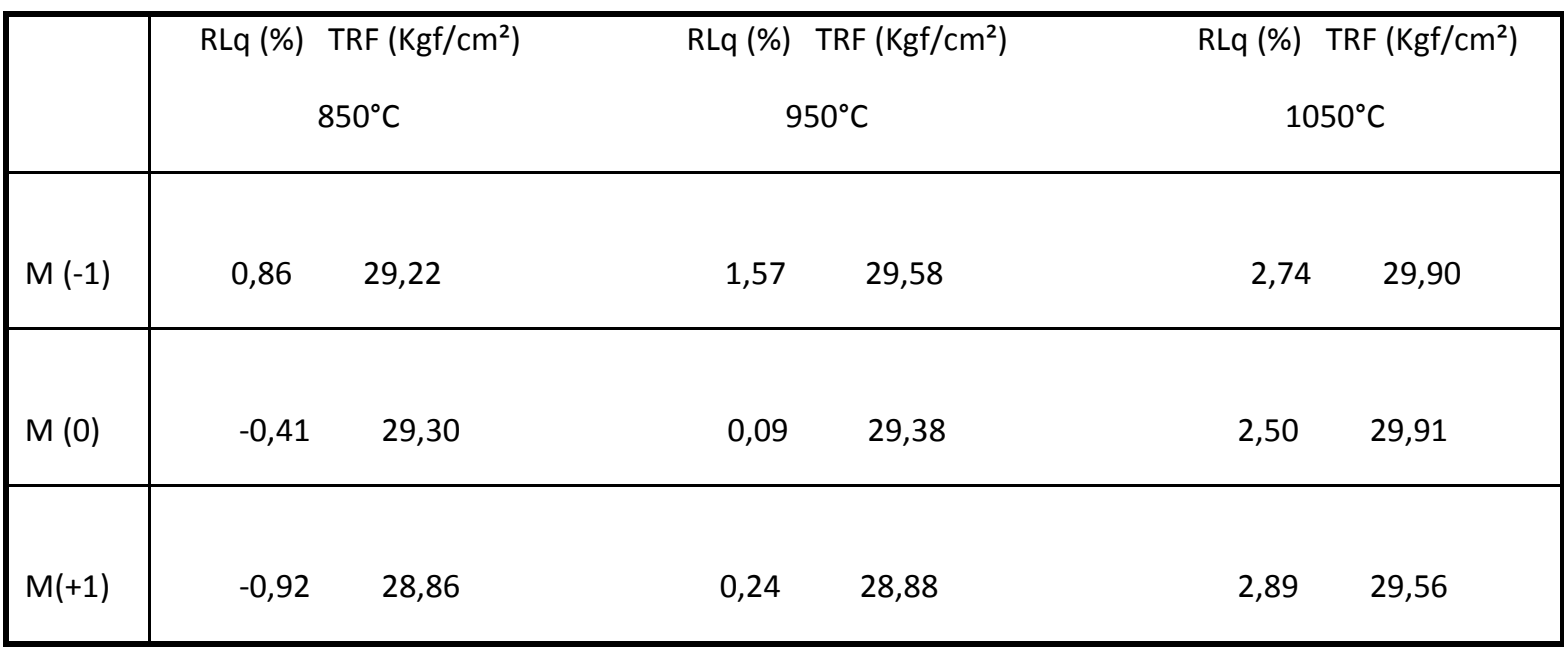

O resultado do ensaio ambiental encontra-se na Tabela 5 e são relativos à determinação do íon manganês no extrato solubilizado. Observa-se que o extrato possui concentrações inferiores ao valor máximo permitido pelo Anexo G da ABNT NBR 10004/2004 (limite máximo de 0,1 mg/l de Manganês). Desta forma, as peças cerâmicas podem ser classificadas como resíduos não perigosos inertes, obtendo a classificação IIB.

Tabela 5: Determinação do íon manganês no extrato solubilizado.

\begin{tabular}{|c|c|c|c|}
\hline \multirow{2}{*}{$\begin{array}{c}\text { Temperatura de } \\
\text { Queima }\left({ }^{\circ} \mathrm{C}\right)\end{array}$} & \multicolumn{3}{|c|}{$\begin{array}{c}|c| \\
\text { (mg/l) }\end{array}$} \\
\cline { 2 - 4 } & $\mathrm{M}(-1)$ & $\mathrm{M}(0)$ & $\mathrm{M}(+1)$ \\
\hline 850 & 0,0902 & 0,0628 & 0,0569 \\
\hline 950 & 0,0047 & 0,0236 & 0,0302 \\
\hline 1050 & 0,0155 & 0,0129 & 0,0169 \\
\hline
\end{tabular}

\section{CONSIDERAÇÕES FINAIS}

Com base nos resultados apresentados, pode-se concluir que a argila estudada é predominantemente caulinítica, contendo quartzo, microclínio e minerais acessórios.

A avaliação das propriedades cerâmicas resistência mecânica e absorção de água demonstrou que as peças cerâmicas com íon manganês estabilizado podem ser utilizadas como tijolo maciço cerâmico de classe B (NBR 07170/1983) e bloco cerâmico de classe 25 (NBR 7171/1992), para todas as formulações queimadas nas temperaturas do tratamento térmico utilizado. 
Os corpos cerâmicos também possuem aplicação para materiais com função de preenchimento estrutural, por exemplo blocos de vedação, pois atendem a NBR 15270 /2005 para blocos Cerâmicos para alvenaria de vedação, que estabelece o critério de absorção de água (AA), especificando que não deve ser inferior a $8 \%$ nem superior a $22 \%$. O ensaio ambiental de solubilidade permitiu classificar todas as peças cerâmicas como materiais inertes (NBR 10004/2004), uma vez que seus extratos solubilizados não apresentaram risco ao meio ambiente.

\section{REFERÊNCIAS BIBLIOGRÁFICAS}

1. ALVES, M. R. F. V; HOLANDA, J. N. F. Reciclagem de borra oleosa através de incorporação em blocos cerâmicos de vedação. Cerâmica Industrial, v. 10, n. 3, 2005.

2. ASSOCIAÇÃO BRASILEIRA DE NORMAS TÉCNICAS. NBR 07170. Tijolo maciço cerâmico para Alvenaria (1983).

3. ASSOCIAÇÃO BRASILEIRA DE NORMAS TÉCNICAS. NBR 10004. Resíduos sólidos Classificação (2004).

4. ASSOCIAÇÃO BRASILEIRA DE NORMAS TÉCNICAS. NBR 10006. Procedimento para obtenção de extrato solubilizado de resíduos sólidos (2004).

5. ASSOCIAÇÃO BRASILEIRA DE NORMAS TÉCNICAS. NBR 13.818. Placas Cerâmicas para Revestimento - Especificação e Métodos de Ensaio (1997).

6. ASSOCIAÇÃO BRASILEIRA DE NORMAS TÉCNICAS. NBR 15270. Componentes Cerâmicos. Parte 1: Blocos Cerâmicos para alvenaria de vedação. Terminologia e requisitos (2005).

7. ASSOCIAÇÃO BRASILEIRA DE NORMAS TÉCNICAS. NBR 7171. Bloco cerâmico para alvenaria, Especificação (1992).

8. BALATON, V. T; GONÇALVES, P. S; FERRER, L. M. Incorporação de resíduos sólidos galvânicos em massas de cerâmica vermelha. Cerâmica Industrial, v. 7, n. 6, 2002.

9. BRASIL, Ministério do meio-ambiente. Conselho Nacional do meio-Ambiente. Resolução $\mathrm{N}^{\circ} 357$, de 17 de março de 2005. Dispõe sobre a classificação de corpos de água e diretrizes ambientais para seu enquadramento, bem como estabelece as condições e padrões de lançamento de efluentes, e dá outras providências. Diário Oficial da República Federativa do Brasil, Brasília, DF, 18 mar. 2005.

10. CÂMARA, C. P. A. Propriedades cerâmicas e imobilização do manganês em cerâmica estrutural. Dissertação de Mestrado, Natal, 2009.

11. CAMARGO, A. C; PORTELA, J. C. S; YOSHIMURA, H. N. Adição de metais tóxicos a massas cerâmicas e avaliação de sua estabilidade frente a agente lixiviante. Parte 1: avaliação das características físicas. Cerâmica Industrial, v. 10, n. 3, 2005.

12. MOREIRA, A. H; OLIVERIA, R. M; LIMA, P. D. S. Efeito da adição do lodo de águas residuais da indústria têxtil nas propriedades de materiais de construção. Cerâmica, v. 47, 2001.

13. VARELA, M. L. et al. Otimização de uma metodologia para análise mineralógica racional de argilominerais. Cerâmica, v. 51, n. 320, p. 388-392, 2005. 